\title{
The University Development Management of the Republic of Kazakhstan in Forming Competitive Environment
}

\author{
Gulnar Iskakova \\ Shakarim State University \\ Semey, Kazakhstan \\ E-mail:gulisk@mail.ru
}

\author{
Deyanira Iskakova \\ L. N. Gumilyov Eurasian National University \\ Astana, Kazakhstan \\ E-mail: deaynira.iskakova@gmail.com
}

\begin{abstract}
The article analyzes factors that have influenced the transformation processes in the higher education system and created a new context for the management activity in this sphere, also considers the formation of competitive environment issues of higher educational institutions in Kazakh educational market. Authors pay special attention to the ongoing development strategies of universities. Two levels of managerial approaches and decisions making process in the higher education field are indicated: the level of the national higher education system (macro level) and the level of the university (micro level). Approved, that competition as a consequence of the commercialization of higher education institutions has become an important institutional state in the system of higher education in Kazakhstan.
\end{abstract}

Keywords-management; university; strategy; competition; factor; effectiveness

\section{INTRODUCTION}

In modern conditions, the management of education mainly is management of process development. Over the past two decades, Kazakhstani universities have been operating against the backdrop of major changes in the social context, in the new social and economic conditions that have emerged in the market of educational services. There are new strategic factors, which in many ways create a new context for management activities, including higher education sphere. Such factors as uncertainty, heterogeneity, limited resources are important to take into account in real management activities. Since was signed Bologna Declaration, Kazakhstani system of higher education has entered a new stage of reforms, the main goal of which is the creation a European educational space that assumes the convertibility of bachelor's and master's degrees, as well as the mobility of graduates in the world labor market.

\section{FACTORS AFFECTING THE DEVELOPMENT OF UNIVERSITIES}

Let's turn to the factors that can influence and actually influenced to the development of universities and higher education system. What should be taken into account in analyzing development process of higher education?
- Obligations for control exist due to the dynamism of the managed system. The sense of management consists in purposeful influence on a dynamic system for realization in necessary transformations. Wherein known that a revolutionary or evolutionary path of development is possible. The revolutionary path associated with the risk of disorganization of the system, the weakening of manageability and serious problems in its recovery, while the evolutionary one seems more attractive. In Kazakhstan, higher education development is carried out in the direction of European standards (the Bologna Process), which were quite difficult introduced and fairly controversially into the post-Soviet educational system. New education initiatives are quite strongly hampered by the current system, and most importantly, by the lack of systematic implementation of reforms.

- The specificity and complexity of managing in the higher education system is determined by the need to implement two opposite functions. First, it is maintenance functioning system, and creation of conditions that ensure the realization of the educational function. Consequently, management activities are directed to eliminate deviations from adopted program to eliminate disturbing impacts. Basis for implementation of this management function were regulatory legal acts of the state (various kinds of standards, norms, programs, etc.). The second function is to ensure the development of the system. But any development presupposes a change, including the established structure, formed links, established norms of activity, therefore the task of ensuring the development of the system in a certain sense contradicts the task of ensuring its functioning.

In real practice, this contradiction is often manifested in management activities. Particular emphasis on the task of development, combined with a weakening to functioning, can lead to the danger of destruction of the system, leading to the emergence of critical situations. In turn, a primary focus on functioning can cause stagnation and stagnation, lead to aggravation of existing contradictions and also to a crisis. 
The experience of the development of higher education of different countries during the last decade shows that it is possible to use the best way to combine the tasks of ensuring the functioning and development of the educational system (Finland, South Korea, China, etc.). The task of managers and not only - to understand and comprehend this experience, trying on it to the Kazakhstan reality. However, on the general background of the rapid modernization of the sphere of higher education in Kazakhstan, there was a noticeable dysfunctionality of the reforms being implemented.

In the context of implementing educational reforms, the skills of organizational analysis of managers both at the macro level and in the micro level - higher educational institutions become a special necessity. The development and implementation of strategic decisions at the university level is one of the main features of the current stage of the reform of higher education. At the same time, it is important to realize the top managers of the higher education system that the changes implemented during the reforms do not necessarily lead to development, understood as a change in the quality of their activities. Development provides modernization and creations of organization development strategy, choosing forward way, when the previous choice has already exhausted itself from the growth point of view. According A. Teslinov "the choice of the development strategy is a convincing arena for the manifestation of the developmental meanings" [1]. As a rule, in the normative documents of many HEIs, the expectations from the development are mainly connected not with the progress, but with growing and improving their business processes, supporting the functioning of their activities. All universities, guided by the State Program for the Development of Education and Science of the RK, have created and adopted their own development strategies, however, as analysis of the content of many of them shows, this is more a strategy for improving educational activities and enhancing its basic indicators. Quite often there is a substitution of development by other processes: the number of joint OP, the number of departed and arrived for academic mobility, the number of published scientific articles with nonzero IF, etc.). If there is no development, accordingly, the university gradually loses its positions, its potential and possibilities decrease, and eventually become less competitive in the educational services market. If development exists, thus exist a new quality of university, in this case increase its stability rate, flexibility and competitiveness. The universities pay less attention to the formation of such an organizational structure capable of carrying out their activities in a dynamically changing environment and the creation of educational programs of a developing type. It has long been understood that not all existing types of education and not all educational programs are evolve.

- During the educational development programs implementation, effect will be deferred and will yield results only after a few years. Considering that education is an open system influenced by a whole set of factors, by the time when the effect of reforms is expected to manifest itself, it can already be influenced by internal and external factors of a different order. As the world practice shows, when implementing reforms in the system of higher education, its development indicators tend to deteriorate in the short term, and certain risks may appear. Social practices show that in the course of reforming the system of higher professional education they directly experienced the influence of reforms, their strengths and weaknesses, both students and teachers.

- The managerial goals in the system of higher education - the formation of a social contract, the development and realization of the potential of the educational system - are carried out, as in any other sphere of managerial activity, through the adoption and implementation of managerial decisions. What are the management solutions for higher education in our country? The high degree of uncertainty, dynamism and instability of change put the management of two large tasks that were not previously encountered in management practice: first, acceleration of the evolution of management systems to a level where they can successfully function on the basis of rapid and flexible solutions; secondly, to increase the adaptive capacity of the participants in the system with a view to accepting new circumstances that arise outside and within the higher education system.

\section{MANAGEMENT APPROACHES AND SOLUTIONS IN HIGHER EDUCATION IN A COMPETITIVE ENVIRONMENT}

Let's consider the most important management approaches in the field of higher education at two levels: the level of the national system of higher education (macro level) in general and the level of the university (micro-level).

What was the characterization of the higher education system in the 2000s? This is the demographic decline that caused the shortage of entrants; commercialization of the educational system, implemented by the state, and formed direct dependence of the financial and material situation of universities on the existing contingent.

At the macro level, such factors as world educational trends, the socio-economic situation in the country, the region and the world, the cultural and historical features of the development of the education system, the social policy of the state, the state and needs of the labor market, the level of development of a competitive environment, the formation of new criteria for the success of universities (ratings), etc.

The competitive struggle of universities includes two interrelated directions: economic struggle (through the cost of offered educational and other services) and symbolic struggle (forming the image of the university, in which the qualities that are attractive to their target audience are accumulated). Practically all universities of Kazakhstan (as far as creating a competitive environment) were experiencing the factor of limited resources (personnel (especially), financial, etc.), which to a significant extent affect the activities of universities today. 
Based on the analysis of management activities to develop additional sources of financial and material resources, innovative leadership activity, it is possible to identify administrative and managerial management models in higher education institutions. The administrative model characterizes the adaptive nature of management, in which management activity is reduced to ensuring the functioning of the university in accordance with regulatory legal acts and financial and material resources established by the Ministry of Education and Science of the Republic of Kazakhstan. The managerial model of management is distinguished by the projective nature of management activities aimed at the development and continuous improvement of basic business processes, the search for sources of additional resources, and the definition of the prospects for the development of the university.

The choice of strategy and tactics of competitive struggle of universities are determined by such factors as the administrative (managerial / managerial) model, structural (status and type of the institution, territorial location, contingent of students) and symbolic (formed image of the university). The nature of interaction between higher education institutions (national and regional, network relations (head university and its affiliates), this or that section of "spheres of influence" between universities and within professional communities, etc., also has a noticeable impact on competition.

In the field of competition, higher education institutions apply four types of management strategies: "optimization", "expansionist", "extensive growth" and "survival". The important goals of the competitive strategies applied by universities are to increase the symbolic (image), cultural (accumulated cultural and cultural achievements of students, employees and partners) and social (trust of employers, students, consumers, the community as a whole) capital of a higher educational institution[2].

The analysis of management strategies of universities in the context of increased competition allows us to say that the leading strategy of many universities is the "optimization" strategy, which is characterized by purposeful activities to maintain a contingent of students while improving the quality of their educational results. Although there is a large share of higher educational institutions that adhere to the "extensive growth" strategy, in which activity is concentrated in increasing number of students recruited regardless of their level of economic and cultural capital.

The applied management strategy of the university determines the totality of these or other tactics - the methods used and channels for attracting entrants. The main groups of tactics include marketing and PR tactics, tactics of "cultivating" entrants and tactics of accessibility for all, etc. So, in the course of implementing an extensive strategy aimed at increasing the number of students in higher education institutions, more ways and channels of attracting entrants are used than in the framework of the optimization strategy [3].

Significant role in the formation of a competitive environment in the system of higher education is played by the state, implementing the strategy of commercialization. The following main administrative actions of the state influenced the creation of a competitive environment. Firstly, rectors of higher educational institutions have to look additional sources in the conditions of a deficit of financing by expanding additional educational services, commercializing the results of scientific activity, and others. Strengthening of competition was facilitated by the introduction of a state educational grant.

It is known, for example, that the aggregate of social functions of the education system usually acts as a social order. At present, the nature of the social order for the education system has changed: the number of "social customers" is noticeable. In the role of the customer, along with the state, employers, the family and an individual citizen are increasingly coming forward. World practice shows that the greatest success is achieved by the state, where the funding channels for universities are diversified. For example, in the US students pay for tuition is $20-30 \%$, the rest is the contribution of central and local bodies, business, various funds, patrons, receipts from orders from outside organizations. In Kazakhstan, introduced since 1999, the mechanism of the state educational grant, according to which money should follow the student, contributed to a certain extent to the formation of a competitive environment in higher education. At the same time, both public and private universities in determining tuition fees were to be based on the cost of a state grant. This mechanism also allowed to support and demand private universities, to develop public-private partnership. For example, in 2016, $759,112.6$ thousand tenge were allocated to provide higher education and after university education, the budget was distributed among 62 Kazakhstani universities, of which national ones were 5 , international ones -1 , state ones -30 , corporatized -14 , private -12 [4]. This mechanism also allowed to support and demand private universities, to develop public-private partnership. In April 2018, a decision was made to give the universities the right to independently determine the cost of training, which was another step towards creating a competitive environment. Opportunity to choose higher education institutions, educational programs and separate educational services allows applicants to state their expectations and requests and makes universities consider their professional orientations and educational expectations. It is important at the same time to divide the state and society as social customers, whose positions do not always and not always coincide.

The growing competitive environment has become an important factor affecting the content of managerial processes and decisions in Kazakhstan's universities: the development of academic freedom, decentralization and autonomization of higher education institutions has been actively pursued. The position occupied by a higher educational institution in the field of competition begins to determine its position in the educational space, especially in the context of the determinism of the financial and material position of the institution, its status, the contingent of students. 
At the "microlevel", the adoption of managerial decisions was concentrated on such processes as the organization of the educational process in the university, the development of educational programs in accordance with the requirements of the labor market and employers, the internationalization of education, the commercialization of scientific projects, etc. The reform of the system of higher education was carried out in the following main areas: increasing the professional competence of the teaching staff, the acquisition by universities of greater independence as an economic entity (on the right of economic management), focused on financial and economic sustainability; improving the quality of educational programs and developing academic and scientific mobility of students and faculty, strengthening the material and technical base and the formation of modern infrastructure; information and technological development, introduction of innovative educational and information technologies into the educational process, and so on.

The position occupied by universities in the field of competition begins to determine its position in the educational space. As the main criteria for determining the position, reflecting the level of competitiveness of universities, it is possible to single out: the rating of the university in international and national rankings, the contingent of students, educational results (the rating of the VOUD, etc.), the percentage of employment, the amount of budgetary and extrabudgetary financial receipts, the results of scientific and activity and their commercialization, the number of foreign students, etc. Many universities in 2012 moved to the regime of economic management, gradually created supervisory boards and board of trustees with serious powers. According to the Ministry of Education and Science of the Republic of Kazakhstan, on October 1, 2016, out of 112 universities in 84 (9 national, 31 state, 1 international, 16 corporatized, 27 private) universities, supervisory boards, boards of trustees and boards of directors, including representatives of the business environment, local executive bodies, well-known and influential graduates, etc. Thus, the share of universities in which corporate governance bodies functioned in 2016 accounted for $75 \%$ of the total number of universities. In 2017, 28 national and state universities operated supervisory boards [5]. They include representatives of the Parliament of the Republic of Kazakhstan, the Ministry of Education and Science, other government agencies, local executive bodies, the National Chamber of Entrepreneurs, representatives of business and industry.

At the same time, in 2016 the Ministry of Education initiated the appointment of rectors through an open competition. Supervisory Board of the University for consideration of the Republican Commission represents at least three candidates. The commission from among the deputies of the Parliament, representatives of state bodies, public organizations under the chairmanship of the Deputy Prime Minister conducts hearings of the Development Programs of the University of the participants of the competition and conducts an interview with them. The candidate for the post of rector of the university is determined by results. In 2017, through a competitive selection, the rector of five state universities was appointed and a competition for the vacant post of rectors of six universities of Kazakhstan is planned.

The Universities together with the Nazarbayev University developed Road maps on the transformation of the Nazarbayev University's experience. The management and teachers of higher educational establishments are trained to work in conditions of academic and managerial autonomy through appropriate courses of professional development. However, some well-established traditional and sustainable management practices that do not meet modern requirements and are ineffective these days have come into conflict with the processes of autonomization and decentralization of governance that have begun but are slowly proceeding. In a number of cases, attempts were made to solve new problems with the help of structures and technologies oriented to high centralization and stability, extrapolating the previous managerial experience to a new situation. Most of the problems that managers of higher education face today are problems of organization, diagnostics of the state, resources, organizational culture, incentives, values, etc. [6]. For example, the Ministry of Education and Science of the Republic of Kazakhstan to attract foreign experts allocated funding for 11 foreign specialists from the universities represented by 22 candidates. Foreign specialists worked in top management of universities during 2016-2018. University practice shows that many foreign specialists participated in the development of educational programs, joint programs, seminars, conferences, courses, lectures, etc. So, in TarSU it. M.H. Dulati developed a joint educational program for the Master's Degree "Mechatronics", Doctoral Studies "Information Systems and Automation" in conjunction with the Lublin Polytechnic University (Poland). However, even here there are problems and missed opportunities. In a number of universities, the invited top manager did not know either the state language or the Russian language, respectively, such manager had serious problems with communications with the teaching staff and the university administration (with the exception of those universities where the teaching staff and top management owned English and other foreign languages (such in universities was, as a rule, less than 1\%). Although budgetary funds have been spent, in most regional universities the expected effect from invited foreign managers has not happened. It is necessary, firstly, the universities themselves to clearly determine which manager (with what professional competencies) they need; secondly, the organizers of such competitions should consider clear criteria for selecting foreign specialists, monitoring their activities according to stated goals and objectives, and evaluating the results of their activities.

In 2015, work was begun to reorganize higher education institutions into non-profit joint-stock companies (hereinafter - NAO). In 2015-2016, they were reorganized in the Nenets Autonomous Okrug. K.I. Satpayev, KazNAU, ZKATU them. Zhangir Khan, Atyrau Institute of Oil and Gas [7]. Implementing the transition of universities to a new organizational and legal form, the Ministry of Education and Science of the Republic of Kazakhstan and universities hope 
that this will attract additional investments for the development of universities, remove the burden from the republican budget, and will promote universities in the context of world trends. Currently, work is underway to further transform 28 state universities in the Nenets Autonomous Region with $100 \%$ state participation.

A serious obstacle to the implementation of the planned changes was a certain resistance to them from the conservative forces of the academic community. As the dynamics of changes in the higher education sphere in Kazakhstan in the near future will remain quite high, it is likely that resistance to these changes for a considerable amount of time can significantly complicate the administrative activities of the university and, accordingly, modernization processes. Here the role of top managers is great, they can not only see the prospects and directions of the university's development, but also organize a team and a team for their implementation.

With all the difficulties, challenges and risks of the unfolded competition of universities gives a positive result: there is a gradual change in the administrative model of university management and the higher education system as a whole to a managerial one. Competitive struggle from adaptive tactics is gradually being transformed in a number of universities into projective management strategies [8].

\section{CONCLUSION}

The aggravation of competition caused by the rapid growth in the number of universities in the 1990s, the decrease in the number of potential entrants in 2005 - 2017, the rapidly changing factors of the external and internal environment of the university, the increased demands and behavioral changes in the consumers of educational services, the need for systematic updating of knowledge and upgrading of qualifications, requires universities to use new tools to increase competitiveness in the market of educational services. Competition as a consequence of the commercialization of universities has become an important institutional state in the system of higher education. Positive results of competition in the system of higher education were, first, the goal-oriented activity of higher education institutions to increase their own competitiveness and sustainability; secondly, the expansion of the offered educational services and the improvement of their quality; thirdly, the wide dissemination in the universities of a managerial management model.

\section{REFERENCES}

[1] A. Teslinov, Why the development and strategies are close? // http://www.teslinov.ru/?p=2229.

[2] S.L. Optner, System analysis for solve problems of business and industry / Stanford L. Optner; Trans. from English., intro. Art. S.P. Nikanorova. - 3rd ed., Stereotype - M.: Concept, 2006. - 206 p .; Increasing the competitiveness of the university on the basis of the formation and implementation of the loyalty program// http://www.dissercat.com/content/povyshenie-

konkurentosposobnosti-vuza-na-osnove-formirovaniya-i-realizatsiiprogrammy.
[3] Ibid.

[4] Report of the Ministry of Education and Science of the Republic of Kazakhstan on the implementation of the State Program for the Development of Education and Science of the Republic of Kazakhstan for 2016-2019// http://edu.gov.kz/ru/deyatelnost/detail.php.

[5] Ibid.

[6] A.V. Davydova, The role of management culture in the formation of a system for effective management of the educational environment // Philosophy of Education. 2011. №6; E. X. Shane Organizational culture and leadership. - St. Petersburg., 2002. -336 p.

[7] Report on the implementation of the Strategic Plan of the Ministry of Education and Science of the Republic of Kazakhstan for 2014-2018// http://edu.gov.kz/ru/deyatelnost/detail.php?ELEMENT_ID=2200.

[8] A. Teslinov, G. Iskakova, A. Sabalakova, Methodology of managerial decisions in the field of higher education. Teaching-methodical manual. Semey, 2013, - 77 p., p. 43. 